\title{
Traffic Noise Changes Due to Water on Porous and Dense Asphalt Surfaces
}

\author{
Elisabete F. Freitas ${ }^{1}$; Paulo A. A. Pereira ${ }^{2}$; Luís G. P. Santos ${ }^{3}$; Adriana P. S. Santos ${ }^{4}$
}

Abstract: The standards for the environmental quality required by the European Community are very demanding in what concerns traffic noise. The interaction tire/road is undoubtedly one of the main sources of traffic noise. Nevertheless, standards do not account for the increase in the noise level caused by rain falling onto road surfaces. Therefore, the aim of this work is to study the effects of water on pass-by noise since the weather is rainy about 25 per cent of the year in Portugal. Thus, it addresses two currently used pavement surfaces, porous asphalt and dense asphalt, constructed in a motorway. A version of the Statistical Pass-By Method was used to assess noise levels with dry and wet surfaces, using a selected set of heavy and light vehicles. The results include analysis of the statistical pass-by index, pressure noise levels and noise spectrum. Noise levels increase significantly with the presence of water, shifting the overall noise by $4 \mathrm{~dB}(\mathrm{~A})$. The benefits of porous asphalt are null for heavy vehicles, particularly at high speeds.

CE Database subject headings: traffic noise, water, porous asphalt, dense asphalt, statistical pass-by method, noise level, noise spectrum.

\footnotetext{
${ }^{1} \mathrm{PhD}$, Assistant Professor, Department of Civil Engineering, University of Minho, Campus de Azurém, 4800-058 Guimarães, Portugal. E-mail: efreitas@ civil.uminho.pt. Telephone: +351253510240. Fax: +351253510217 .

${ }^{2} \mathrm{PhD}$, Professor, Department of Civil Engineering, University of Minho, Campus de Azurém, 4800-058 Guimarães, Portugal. E-mail: ppereira@ civil.uminho.pt. Telephone: +351253510240. Fax: +351253510217 .

${ }^{3} \mathrm{PhD}$, Professor, Department of Civil Engineering, , University of Coimbra, Rua Luís Reis Santos, 3030788 Coimbra, Portugal. Email: picsan@ dec.uc.pt. Telephone: +351239797143. Fax: +3512397971423.

${ }^{4}$ MSc, Civil Engineer, AENOR - Autoestradas do Norte, Rua Antero de Quental, 381 - $3^{\circ}$ Apartado 5026, 4455-586 Perafita, Matosinhos, Portugal. Email: asantos@ aenor.pt. Telephone: +351229997490. Fax: +351229940535 .
} 


\section{Overview}

From a technical viewpoint, traffic noise may be considered as the sum of the noise produced by all types of vehicles on roads and highways. The noise produced by the tire/road surface contact is the predominant noise source when considering speeds above 40 to $50 \mathrm{~km} / \mathrm{h}$ (Bendtsen et al., 2006).

The tire/road surface noise generation mechanisms derive from radial and tangential vibrations of the tire tread as a result of the impact and the adhesion of the treads on the surface along with air vibrations around the tire and in the grooves and cavities of its treads. These mechanisms may be amplified by the horn effect and by the acoustical and mechanical impedance of the surface (Sandberg at al., 2002), which are affected by the following parameters:

- surface characteristics - aggregate gradation (Bendtsen 2006), texture (Sandberg et al. 2002), porosity, age (FEHRL 2006), surface stiffness (Houari 2004), distresses (Berengier 2005);

- vehicles - type of vehicle (Descornet 2005), tire (Pucher et al. 2006), speed (Haberl et al. 2005);

- weather conditions - wind (Watts 2005), temperature (Anfosso-Lédée 2001), water on the surface (Sandberg at al. 2002);

- drivers' behaviour (Mancosu 1999).

Several studies carried out in roads with different types of surface and age have usually shown that dense asphalt concrete, stone mastic asphalt and surface dressings are the ones that generate more noise contrasting with double and single porous asphalt, thin 
layers and poroelastic surfaces (Anderson et al. 2006; Descornet et al. 2006; Bartolomaeus 2006) when the surface is dry.

The performance of these surfaces, including the most silent, may considerably be affected by the presence of water, which is a negative aspect in rainy regions.

According to Sandberg et al. (2002) the following wet surface noise generation mechanisms may exist:

- the displacement of water in front of the contact patch (bow wave and ejected splash);

- the compression of water (although water is not very compressible) in the tread pattern channels and following jet spraying out of the contact patch;

- ejected water hitting objects on the vehicle body, either in lump water "jets" or in the form of droplets;

- the impact of rubber blocks on the water surface at the leading edge;

- the breaking of adhesion bonds between rubber and water trailing edge.

Water may increase the vehicle noise emission level under dry conditions up to 15 $\mathrm{dB}(\mathrm{A})$ in medium and high frequencies, but, according to Descornet (2000), in certain cases there is a decrease in low and medium frequencies when considering trucks exclusively. Phillis and Abbott (2001) found that Hot Rolled Asphalt, which is an asphalt concrete with a very low macrotexture usually used as wearing course, did not increase the noise level whenever there existed water on the surface. Later, Jiménez (2006) concluded that for a speed of $80 \mathrm{~km} / \mathrm{h}$ and for a wet surface dense asphalt is about $4 \mathrm{~dB}(\mathrm{~A})$ noisier than porous asphalt and $5 \mathrm{~dB}(\mathrm{~A})$ noisier than a gap graded 
mixture. In its turn, the gap graded mixture is about $1 \mathrm{~dB}(\mathrm{~A})$ more silent than the porous asphalt.

Despite these results, the impact of water on the surface in relation to noise level has not been studied in depth up to the present.

Since in Portugal the weather is rainy about $25 \%$ of the year and the most common surfaces are dense asphalt concrete layers which have been replaced lately by single porous asphalt layers in motorways, namely at the more rainy north (above Tagus river), the study of the effect of the water on traffic noise presented hereafter takes these two types of surface into consideration.

\section{Study methodology}

The study was carried out in the A41-IC24 motorway, in the north of Portugal. As this motorway was in construction, it was possible to set two consecutive road sections, one with a dense asphalt surface and the other with a porous asphalt surface. This allowed the adoption of the Controlled Pass-by method, which, in its turn, permitted the control of several testing factors such as category, speed and load of vehicles, number of tests by each type of vehicle, type and the wearing of the tires, noise generated by the engine and the conditions of the surface (wet or dry). The wet condition of the surface was achieved by spreading water with a water supplier truck. A microphone was positioned at $1.2 \mathrm{~m}$ above the pavement surface and $7.5 \mathrm{~m}$ from the centre of the carriageway. For each pass-by the maximum noise level, and noise spectrum and the vehicle speed were measured. The weather conditions (wind speed, temperature) and the surface 
temperature were measured every 15 minutes. Surface properties such as mean profile depth and friction were also measured.

\section{Testing conditions}

\subsection{Road sections and surface characteristics}

For the selection of the testing sites the recommendations of the ISO Standard 118191:1997, such as the presence of high reflective objects and the slope of the road, were followed except for what concerns the age of the surface. In terms of security, due attention was paid to the length required for accelerating and breaking. Thus, two consecutive road sections, whose surfaces are porous asphalt (PA) and dense asphalt (DA), were built in the A41-IC24 motorway. The porous asphalt surface was constructed over all the surface of the motorway; the dense asphalt surface was constructed for comparison purposes and removed afterwards. The total length of each testing section was $40 \mathrm{~m}$. Figure 1 shows the location of the testing sites, the testing geometry and the microphone position. Figure 2 shows the aspect of the surface.

The main properties of the mixtures, such as maximum aggregate size, porosity, binder content, were provided by the Motorway Owner (Table 1). The Mean Texture Depth was measured by the "Sand Patch Method" (NLT 385/87: 2000) and Friction was measured through the British Pendulum (ASTM E303 - 93: 2003), every $12.5 \mathrm{~m}$ at three cross section locations. Table 1 shows the range of the results for these properties.

\subsection{Testing vehicles and speed}


The tests were performed by using six types of vehicle (Figure 3) grouped into the following categories, as recommended by the standard ISO 118919-1:1997(E):

- Category 1: cars and other light vehicles $\left(\mathrm{L}_{1}\right)$ - 1 Citroën XSara, 1 Volvo S40, 1 Nissan Terrano, 1 Renault Traffic;

- Dual-axle heavy vehicles $\left(\mathrm{L}_{2 \mathrm{a}}\right)-1$ Mercedes;

- Multi-axle heavy vehicles $\left(\mathrm{L}_{2 b}\right)-1$ Scania.

The testing speeds chosen considered the road category and the legal speed limitations for each type of vehicle. Therefore, two levels were set in accordance with the road speed categories recommended by ISO 118919-1:1997(E):

- Medium road speed - average speed of $65 \mathrm{~km} / \mathrm{h}$ to $99 \mathrm{~km} / \mathrm{h}$, associated with suburban areas or rural highways;

- High road speed - more than $100 \mathrm{~km} / \mathrm{h}$, associated with motorway traffic in rural or suburban areas.

For heavy vehicles the medium road speed level was adopted. For light vehicles the medium and high speed level were adopted. A total of 207 valid vehicle pass-bys were effectuated along the testing section.

\subsection{Weather}

Weather factors such as temperature, wind speed and water on the surface should be considered when measuring traffic noise in relation to pavement surfaces. Generally, temperature increases or wind speed decreases reduce the noise levels measured. This 
fact means that reference values need to be taken into account. Directive 2001/43/EC of the European Parliament recommends the correction of the temperature to the reference value of $20^{\circ} \mathrm{C}$ and testing with wind speeds below $5 \mathrm{~m} / \mathrm{s}$. Throughout the testing period the wind speed was always inferior to $4 \mathrm{~m} / \mathrm{s}$ and the testing temperature range would have implied a correction of $\pm 0.22 \mathrm{~dB}(\mathrm{~A})$, which was not taken into account. In what respects to water on the surface, despite its important effect no corrections are recommended.

\section{Analysis of results}

Three approaches have been considered in relation to the analysis of results: i) sound pressure level versus speed (this analysis is important for the establishment of speed limits in urban areas, which should take into account the surface condition, dry and wet, aiming at controlling the overall noise level); ii) noise spectrum (this analysis intended to find possible improvements regarding design, properties of the materials and construction quality of the mixes); iii) effect of the water on the performance of dense asphalt and porous asphalt mixes.

In order to facilitate the comparison of results, two reference speeds were selected for each type of vehicle. For light vehicles, reference speeds of $80 \mathrm{~km} / \mathrm{h}$ and $110 \mathrm{~km} / \mathrm{h}$ were chosen within the medium speed level and the high speed level respectively. For heavy vehicles, reference speeds of $70 \mathrm{~km} / \mathrm{h}$ and $85 \mathrm{~km} / \mathrm{h}$ were chosen, both within the medium speed level. These reference speeds were also used to estimate the overall effect of water on the performance of the mixes under study by means of the Statistical Pass-By Index. 


\subsection{Sound pressure level versus speed}

Figure 4 depicts the sound pressure levels measured within the speed levels adopted, medium (m) and high (h), with dry (d) and wet (w) surfaces for each vehicle category $\left(\mathrm{L}_{1}, \mathrm{~L}_{2 \mathrm{a}}, \mathrm{L}_{2 \mathrm{~b}}\right)$. A general approach to the results obtained shows that the increase of the sound pressure levels is not only a function of speed, but also of the type of vehicle. Noise increases for light vehicles more than for heavy vehicles as far as speed increases. For light vehicles and both speed levels, four noise levels can be distinguished in an increasing order when the following combination of type of surface and surface condition exists:

a) dry porous asphalt;

b) dry dense asphalt;

c) wet porous asphalt;

d) wet dense asphalt.

However, in relation to heavy vehicles porous asphalt layers (PA) and dense asphalt layers (DA) have similar results either with wet or with dry surfaces. A more accurate analysis of the effect of water when measuring noise was made based on the calculation of the sound levels which correspond to the reference speeds adopted (Tables 2, 3 and 4).

The set of sound pressure levels on wet surface conditions is clearly higher for all types of vehicle and increases with speed. For light vehicles, the differences encountered for the DA and the PA are, correspondingly, about $7.5 \mathrm{~dB}(\mathrm{~A})$ and $6 \mathrm{~dB}(\mathrm{~A})$ for both reference speeds. In relation to heavy vehicles the change in noise level is significant 
only for vehicles of category L2a at $85 \mathrm{~km} / \mathrm{h}$, with $4.9 \mathrm{~dB}(\mathrm{~A})$ for the $\mathrm{DA}$ and $3.2 \mathrm{~dB}(\mathrm{~A})$ for the PA.

When sound levels of DA and PA are compared (Table 4), differences at lower speeds are generally significant for all categories of vehicles and surface conditions (wet, dry). At higher speeds $(85 \mathrm{~km} / \mathrm{h}$ and $110 \mathrm{~km} / \mathrm{h})$, only light vehicles had a significant difference (about $3 \mathrm{~dB}(\mathrm{~A})$ ).

\subsection{Sound pressure level versus frequency}

Figures 5 and 6 depict the noise spectrum in 1/3 octave bands for light vehicles at high speed and medium speed levels correspondingly and Figure 7 for heavy vehicles at medium speed levels.

When the surface is dry, approximately linear ascending segments and linear descending segments may describe the spectrum. Variations due to the tire tread impact and noise absorption by the surface are fairly low. The maximum noise level ("cross frequency") occurs within the frequency range of $[800,1000] \mathrm{Hz}$ for light vehicles and near $500 \mathrm{~Hz}$ for heavy vehicles. In this case the results are in accordance with those obtained by other authors, such as Olms et al. (1999), Sandberg et al. (2002) and Anfosso-Lédée et al. (2003).

When the surface is wet, the sound pressure level that corresponds to the "cross frequency" only increases significantly for light vehicles. The following decreasing linear segment becomes generally non linear showing a very slight decrease at high 
frequencies. In this case, an important scatter occurs for light vehicles and the PA. This might be the result of the variation of the amount of water inside the PA, due to the technique used (watering the surface) in conjunction with speed variations, what interferes with the sound absorption capacity of the surface. Higher speeds show slighter decreases at high frequencies.

For heavy vehicles category L2a and L2b, water increased the tire treads vibration, whose effect on noise spectrum can be seen on Figure 7, at low frequencies (below $500 \mathrm{~Hz}$ ). Furthermore, PA registered a flatter non linear segment at high frequencies.

\subsection{Statistical pass-by index}

The relative influence of the road surface can be obtained by the Statistical Pass-By Index (SPBI), which provides a combined level of the road surface influence on traffic noise considering different types of vehicle and a certain level of speed (Equation 1).

$$
\mathrm{SPBI}=10 \log \left[\mathrm{W}_{1} \times 10^{\mathrm{L}_{1} / 10}+\mathrm{W}_{2 \mathrm{a}}\left(\mathrm{V}_{1} / \mathrm{V}_{2 \mathrm{a}}\right) \times 10^{\mathrm{L}_{2 \mathrm{a}} / 10}+\mathrm{W}_{2 \mathrm{~b}}\left(\mathrm{~V}_{1} / \mathrm{V}_{2 \mathrm{~b}}\right) \times 10^{\mathrm{L}_{2 \mathrm{~b}} / 10}\right]
$$

where:

$$
\begin{aligned}
\text { SPBI }= & \text { is the Statistical Pass-by Index, for a standard combination } \\
& \text { of light and heavy vehicles; } \\
\mathrm{L}_{1}, \mathrm{~L}_{2 \mathrm{a}}, \mathrm{L}_{2 \mathrm{~b}}= & \text { are the Vehicle Sound Levels for vehicle categories } 1,2 \mathrm{a} \\
& \text { and } 2 \mathrm{~b} ; \\
\mathrm{W}_{1}, \mathrm{~W}_{2 \mathrm{a}}, \mathrm{W}_{2 \mathrm{~b}}= & \text { are the weighting factors, which are equivalent to the } \\
& \text { assumed proportions of vehicle categories in the traffic; }
\end{aligned}
$$




$$
\mathrm{V}_{1}, \mathrm{~V}_{2 \mathrm{a}}, \mathrm{V}_{2 \mathrm{~b}}=\text { are the reference speeds of individual vehicle categories. }
$$

For the calculation of the SPBI the proportion of the number of vehicles pass-bys recommended at ISO 118919-1:1997(E) for each vehicle category was taken into account. The vehicle sound levels (L) for each category were determined based on the regression line of the maximum A-weighted sound pressure level versus the logarithm of speed for the adopted reference speeds. The data used for the calculation of the SPBI are presented in Tables 2 and 3. For heavy vehicles, the same data set was used for the estimation of the noise levels at reference speeds of $70 \mathrm{~km} / \mathrm{h}$ and $85 \mathrm{~km} / \mathrm{h}$, which correspond to the medium speed level and the high speed level respectively. The weighting factors which correspond to vehicles $\mathrm{L}_{1}, \mathrm{~L}_{2 \mathrm{a}}, \mathrm{L}_{2 \mathrm{~b}}$ were: $0.8,0.1$ and 0.1 for medium speed levels and 0.8, 0.075 and 0.225 for high speed levels (ISO 1189191:1997(E)).

Table 5 presents the calculated Statistical Pass-By Indexes and the differences found for the SPBI considering the same type of surface and different surface condition and different type of surface and the same surface condition.

For both speed levels and type of surface, water has shown to originate an increase of $4 \mathrm{~dB}(\mathrm{~A})$ on the SPBI.

In what concerns medium speed levels, there existed a difference of $3 \mathrm{~dB}(\mathrm{~A})$ when comparing dense asphalt and porous asphalt under wet/dry surface conditions This means that using a porous asphalt surface instead of a dense asphalt surface provides an acceptable overall noise reduction under wet/dry conditions. Regarding high speed 
levels, the differences encountered were not significant. Regardless dry or wet surface conditions the reduction of the overall noise by means of a porous asphalt layer is very limited.

The analysis provided by the SPBI clearly shows that water has a major impact on the overall traffic noise and, therefore, it should be included in methodologies used for the assessment of environmental noise, particularly in rainy countries.

\section{Conclusions}

This paper aimed at better understanding the effect of water on noise by making an enhanced analysis of the noise results which included its spectrum. This study was carried out in a motorway in which two road sections, whose surfaces were made of dense asphalt and porous asphalt, were newly constructed. The testing methodology was based on the Controlled Pass-by method and the results were analysed considering three approaches. The following main conclusions have been attained:

- The increase of the sound pressure levels is a function of the speed and the type of vehicle. Light vehicles show a higher increase at higher speeds;

- All types of vehicle show high sound pressure levels on wet surfaces, at medium and high speed levels. However, heavy vehicles show significant differences in noise levels in relation to dry surfaces only at high speed level, increasing noise by $5 \mathrm{~dB}(\mathrm{~A})$.

- For light vehicles and both speed levels, four noise levels can be clearly distinguished in an increasing order of noise production which correspond to the 
following combination of surface condition/type of surface: 1 - dry porous asphalt; 2 - dry dense asphalt; 3 - wet porous asphalt; 4 - wet dense asphalt.

- Heavy vehicles are less sensitive than light vehicles to the type of surface and have fairly similar results either for wet or dry surfaces at medium speed level. At high speed level differences can reach $4.9 \mathrm{~dB}(\mathrm{~A})$.

- The noise spectrum for dry surfaces can be described by two approximately linear segments with a "cross frequency", whose range is [800, 1000] $\mathrm{Hz}$ for light vehicles and near $500 \mathrm{~Hz}$ for heavy vehicles;

- When the surface is wet, the "cross frequency" sound pressure level increases significantly only for light vehicles. The following linear segment becomes non linear being responsible for noise increase.

- The scatter of the non linear segment is higher for light vehicles on porous asphalt (PA).

- For heavy vehicles, there are no differences on the non linear segment when the surface is wet;

- Water causes an increase of $4 \mathrm{~dB}(\mathrm{~A})$ on the SPBI on both surfaces;

- The SPBI can change by $7 \mathrm{~dB}(\mathrm{~A})$ when the conjunct effects of water and the type of surface are taken into account.

This paper clearly showed to what extent water on the road surface affects traffic noise, considering that the flow of heavy and light vehicles is different in rural and urban areas. Further research should focus on innovative road surfaces capable of mitigating traffic noise, particularly in heavy trafficked urban roads under wet conditions, when the noise increase really affects life quality of neighbourhoods, supporting environmental management strategies. 


\section{REFERENCES}

Jiménez, F. P. (2006). “Medidas de Ruido de Pavimentos en Condiciones Seco y Mojado”. Incidencia de la capa de rodadura en la reducción del ruido del tráfico en carreteras, Jornadas Técnicas, CEDEX, Madrid.

Phillips S. and Abbott P. (2001). "Factors Affecting Statistical Pass-By Measurements". Proceedings of Inter-Noise, Hague, Netherlands.

Anfosso-Lédée F. (2001). “The Effect of Temperature on Pass-By Noise”. LCPC, Nantes, France.

Anfosso-Lédée, F., Bérengier, M. et Boze, D. (2003). "L’évaluation Expérimentale des Performances Acoustiques des Revêtements de Chaussée: où en est-on?". Magazine Acoustique \& Techniques, numéro 32, 11-17.

Andersen B., Bendtsen H. and Larsen L. (2006). “Acoustic Performance of Low-Noise Road Pavements". SILVIA Project Report, Denmark.

ASTM E303-93 (2003). “Standard Test Method for Measuring Surface Frictional Properties Using the British Pendulum Tester”. Volume 04.03, Road and Paving Materials; Vehicle-Pavement Systems. American Society for Testing and Materials.

Bartolomaeus W. (2006). "The Potential of Different Road Surface Designs in Road Traffic Noise Reduction - European Experience on Pavement Influence on Noise 
(Experiences in Germany)". Incidencia de la capa de rodadura en la reducción del ruido del tráfico en carreteras, Jornadas Técnicas, CEDEX, Madrid.

Bendtsen H. and Andersen B. (2005). "Noise-Reducing Pavements for Highways and Urban Roads - State of the Art in Denmark. Journal of the Association of Asphalt Paving Technologists, Association of Asphalt Paving Technologists, Vol. 74.

Bendtsen H. (2006). "Review of Existing Low Noise Surfaces". Incidencia de la capa de rodadura en la reducción del ruido del tráfico en carreteras, Jornadas Técnicas, CEDEX, Madrid.

Berengier M. (2005). "Detection Systems for Pavement Discontinuities”. Silence, European Commission DG Research. Available at http://www.silenceip.org/site/fileadmin/public_reports/SILENCE_F.D7_080206.pdf.

Descornet G. (2005). "Low-Noise Road Surfaces - European State of the Art". Journal of the Association of Asphalt Paving Technologists, Association of Asphalt Paving Technologists, Vol. 74.

Descornet G. and Goubert L. (2006). "Noise Classification of Road Pavements, Task 1: technical background information 1". Draft Report 05, Directorate-General Environment, European Commission.

Descornet, G. (2000). “Wet Road Influence on Vehicle Noise”, Proceedings of Internoise, Nice, France. 
FEHRL (2006). "Guidance Manual for the Implementation of Low-Noise Road Surfaces", SILVIA - sustainable road surfaces for traffic noise control. FEHRL report 2006/02. Forum of European National Highway Research Laboratories, Brussels, Belgium.

Haberl J., Lengheim T, Pucher E., Litzka J., Bendtsen H., Watts G., Parry A., AnfonssoLédée F., Sandberg U., LeLong J., Hamet J-F., Van Blokland G-J., Kuijipers A., Ejsmont J. and Mioduszeweski P. (2005). "Integration of Low-Noise Pavements with other Noise Abatement Measures". Report, SILVIA-TUW-052-04-WP5-220305, Forum of European National Highway Research Laboratories, Brussels, Belgium.

Houari A. (2004). "Influence de la Rigidité de Chaussée sur le Bruit de Contact Pneumatique-Chaussée". Thèse de doctorat de l'Université de Technologie de Compègne.

ISO 11819-1:1997. «Acoustics - Method for Measuring the Influence of Road Surfaces on Traffic Noise - Part 1: Statistical Pass-By Method". International Organisation for Standardisation (ISO), Geneve, Switzerland.

Mancosu F. (1999). “TINO Project: an Overview”. $1^{\circ}$ International Colloquium on Vehicle Tyre Road Interaction "The Noise Emission”, Roma, Italy.

NLT 335/87 (2000). "Medida de la Textura Superficial por el Método del Circulo de Arena". 
Olms, H. and Breuer, B. (1999). "MARGA - A New Tool for Tyre/Road-Noise Analysis". Proceedings of the 1st International Colloquium on Vehicle Tyre Road Interaction, Rome, Italy.

Pucher E., Litzka J., Haberl J., Girard J., Ejsmont J., Lelong J. Hamet J-F., Sandberg U., Bendtsen H., Watts G., Parry A., Blockland G. and Kuijpers A. (2006).

"Recommendations on Specifications for Tyre and Vehicle Requirements". SILVIA Project Report, TUW-039-02-WP5-120304, Forum of European National Highway Research Laboratories, Brussels, Belgium.

Sandberg U. and Ejsmont J. (2002). "Tyre / Road Noise Reference Book". Informex SE - 59040, Kisa, Sweden (www.informex.info) 


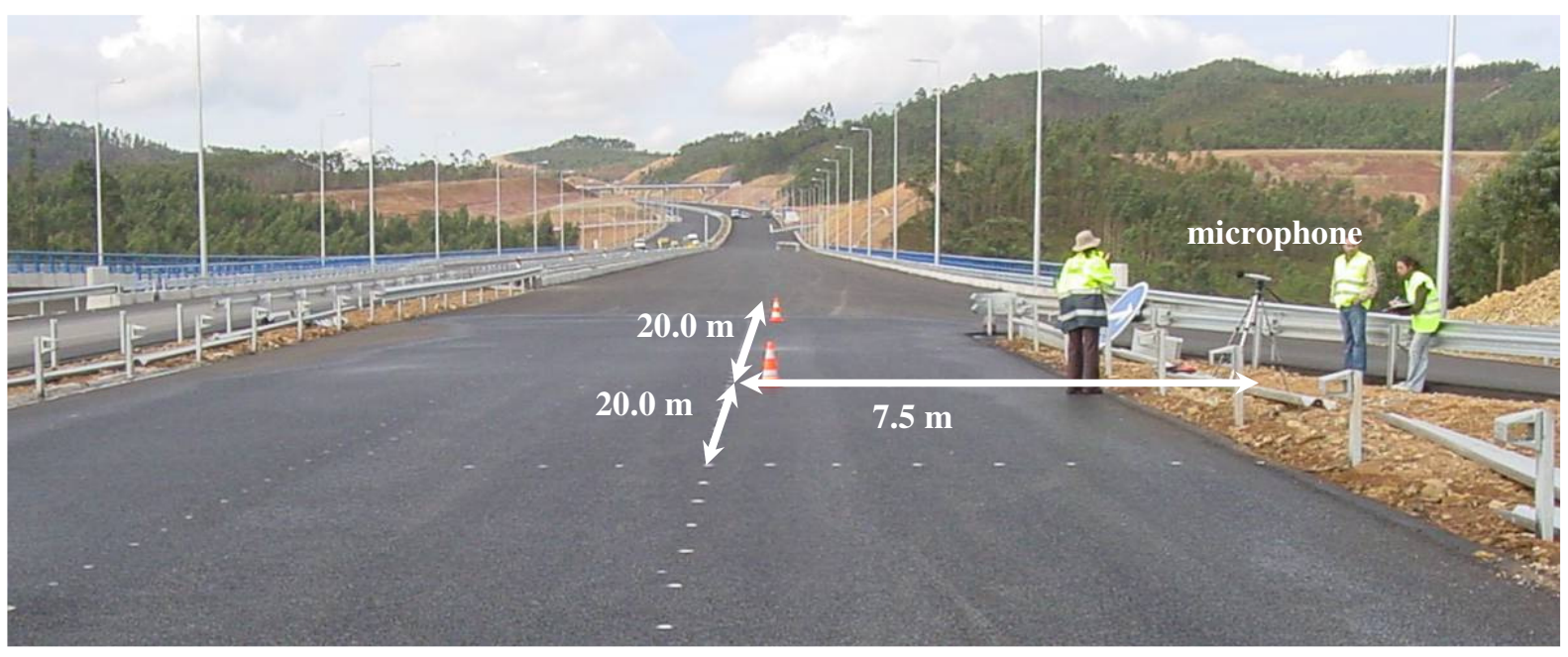

Figure 1 - Location of the sections and layout of the tests 


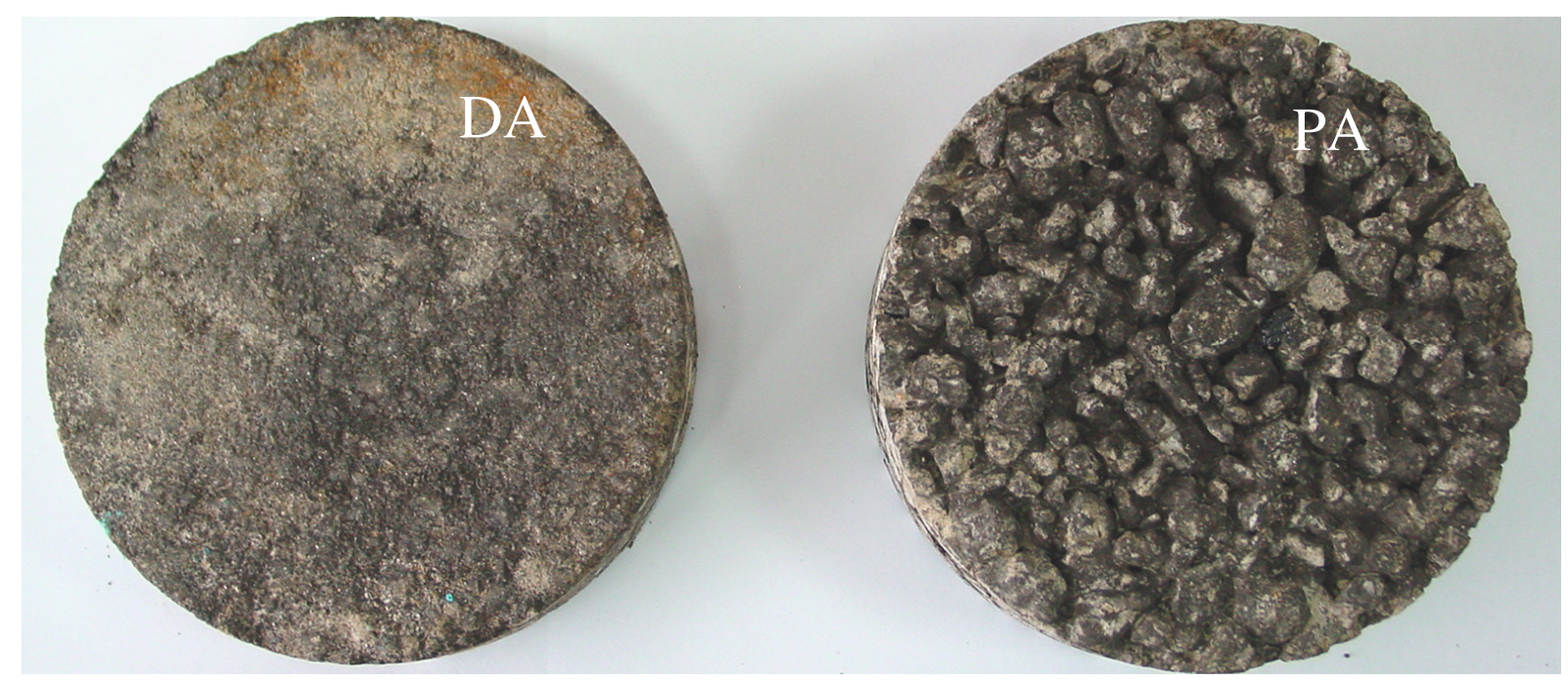

Figure 2 - Aspect of the wearing course (DA - Dense Asphalt, PA - Porous Asphalt) 


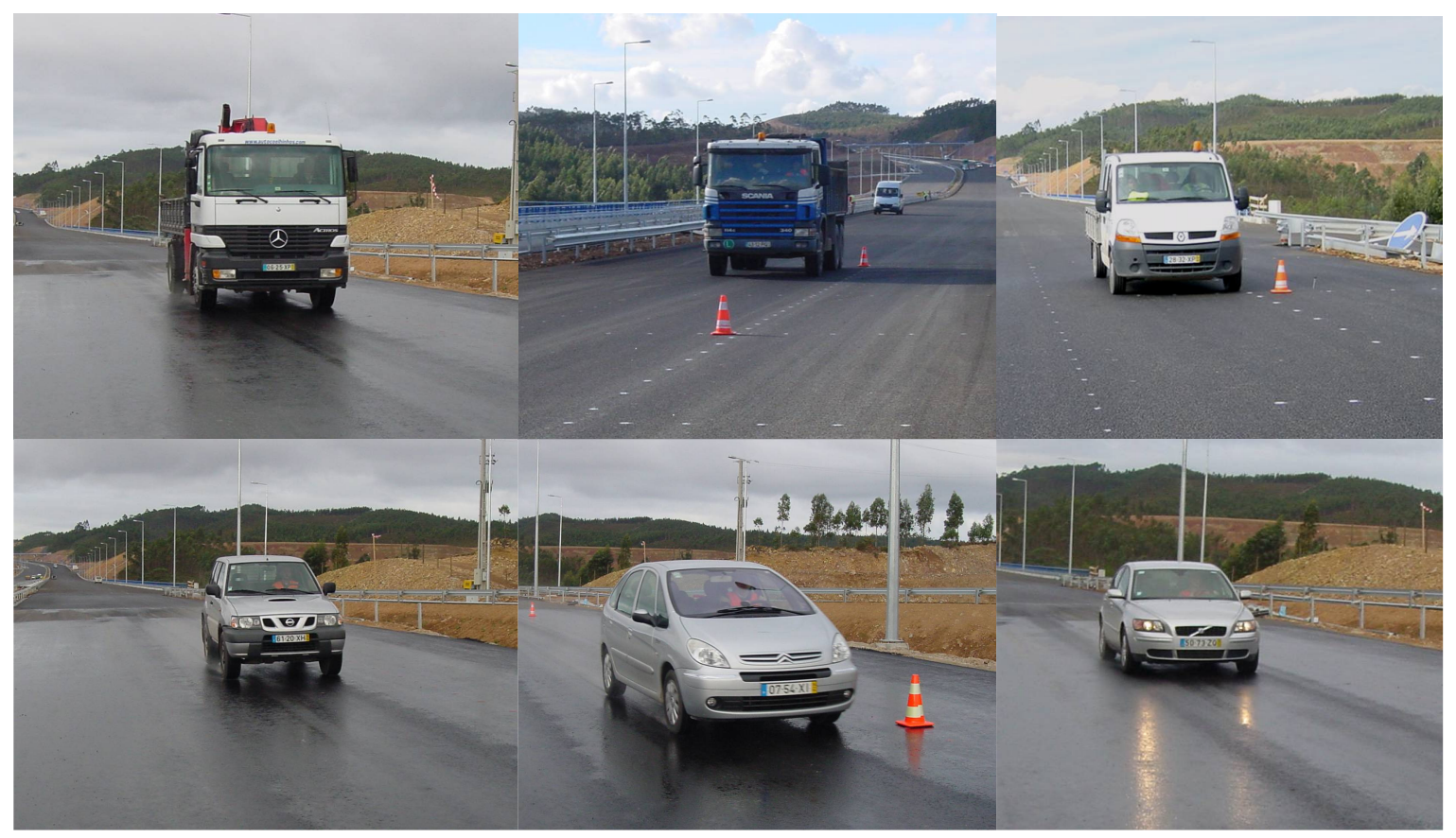

Figure 3 - Testing vehicles 

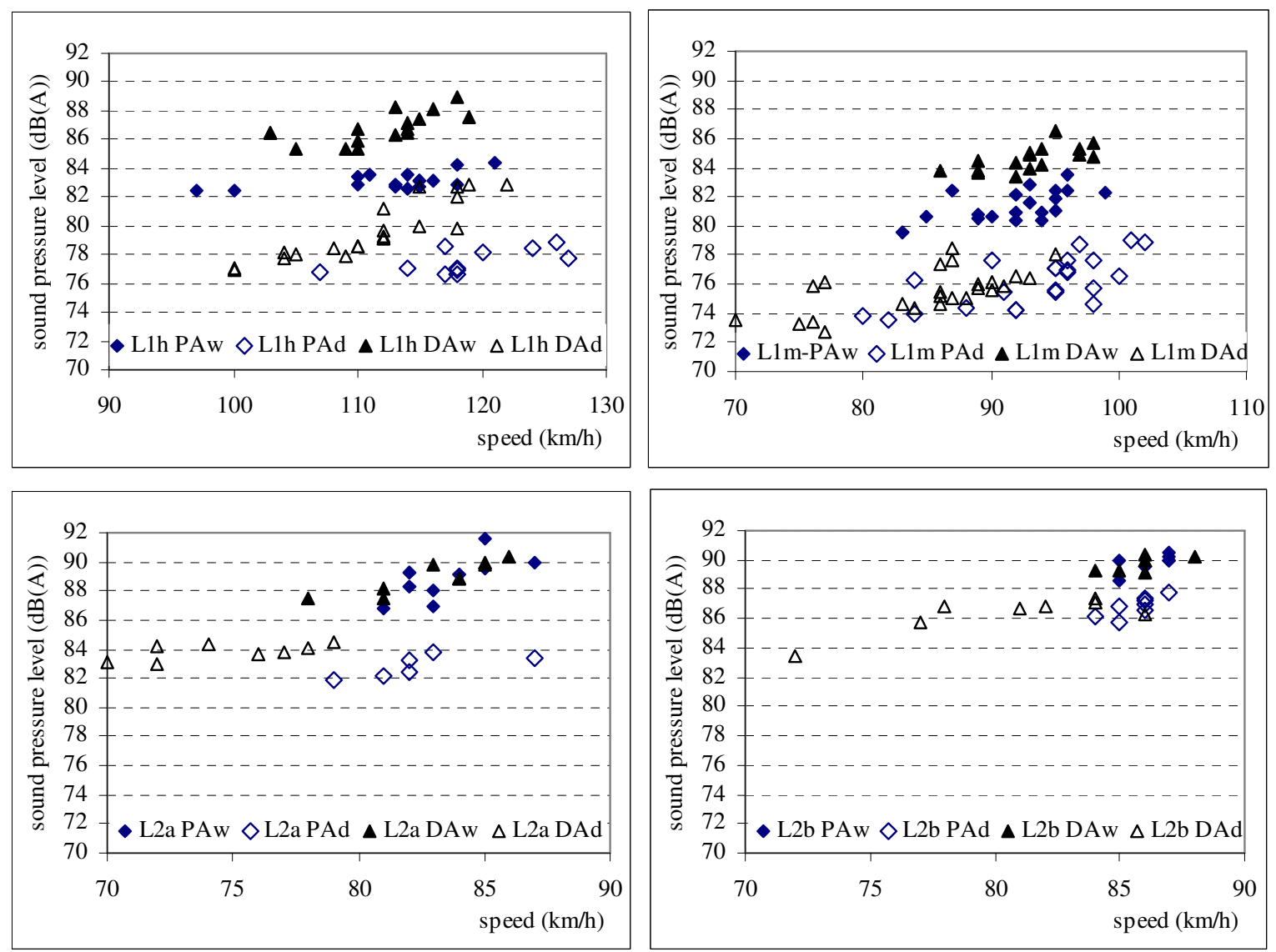

Figure 4 - Maximum sound pressure level for vehicles at medium and high speed levels with dry and wet surfaces 

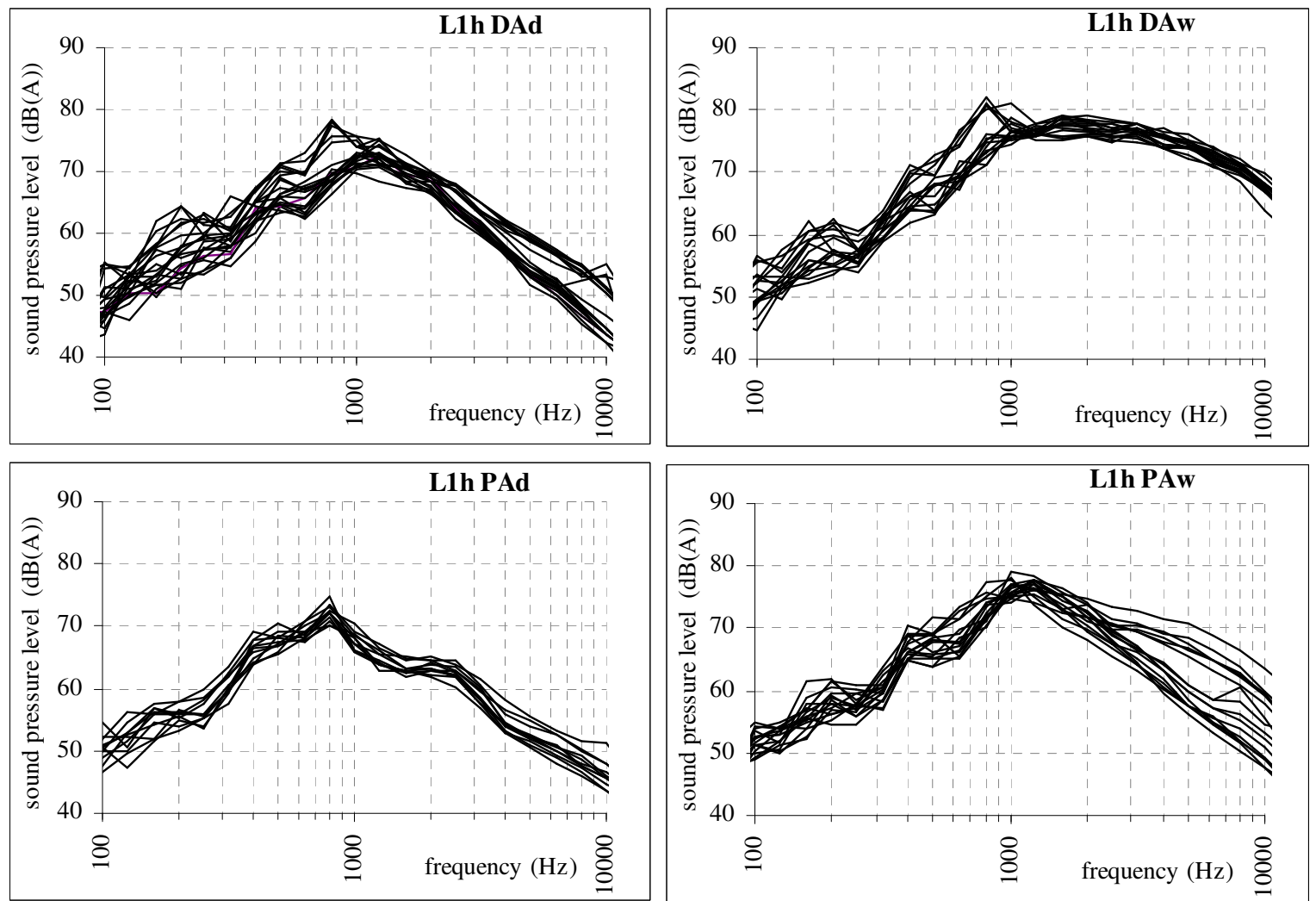

Figure 5 - Noise spectrum for the light vehicles (high speed level) 

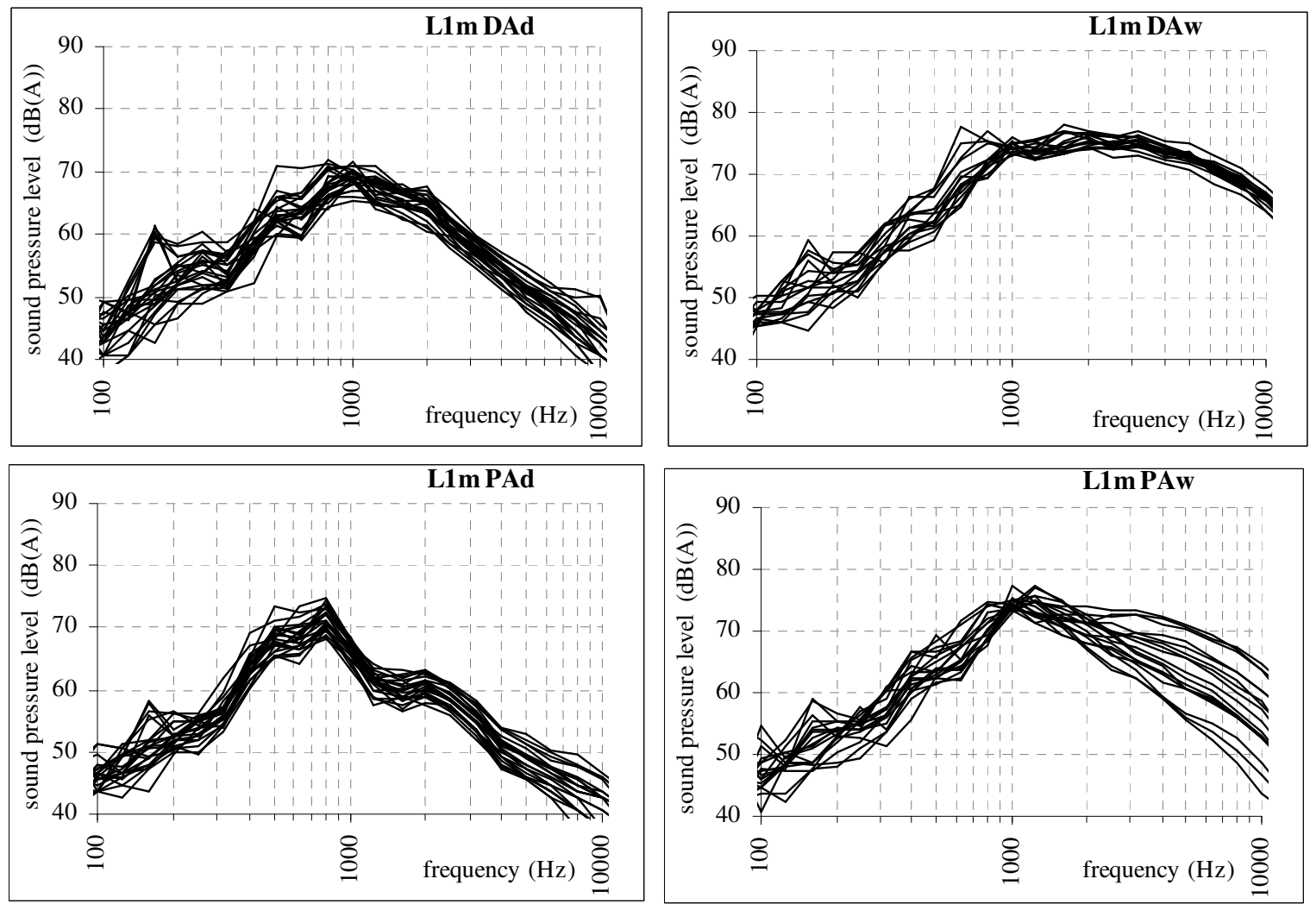

Figure 6 - Noise spectrum for the light vehicles (medium speed level) 

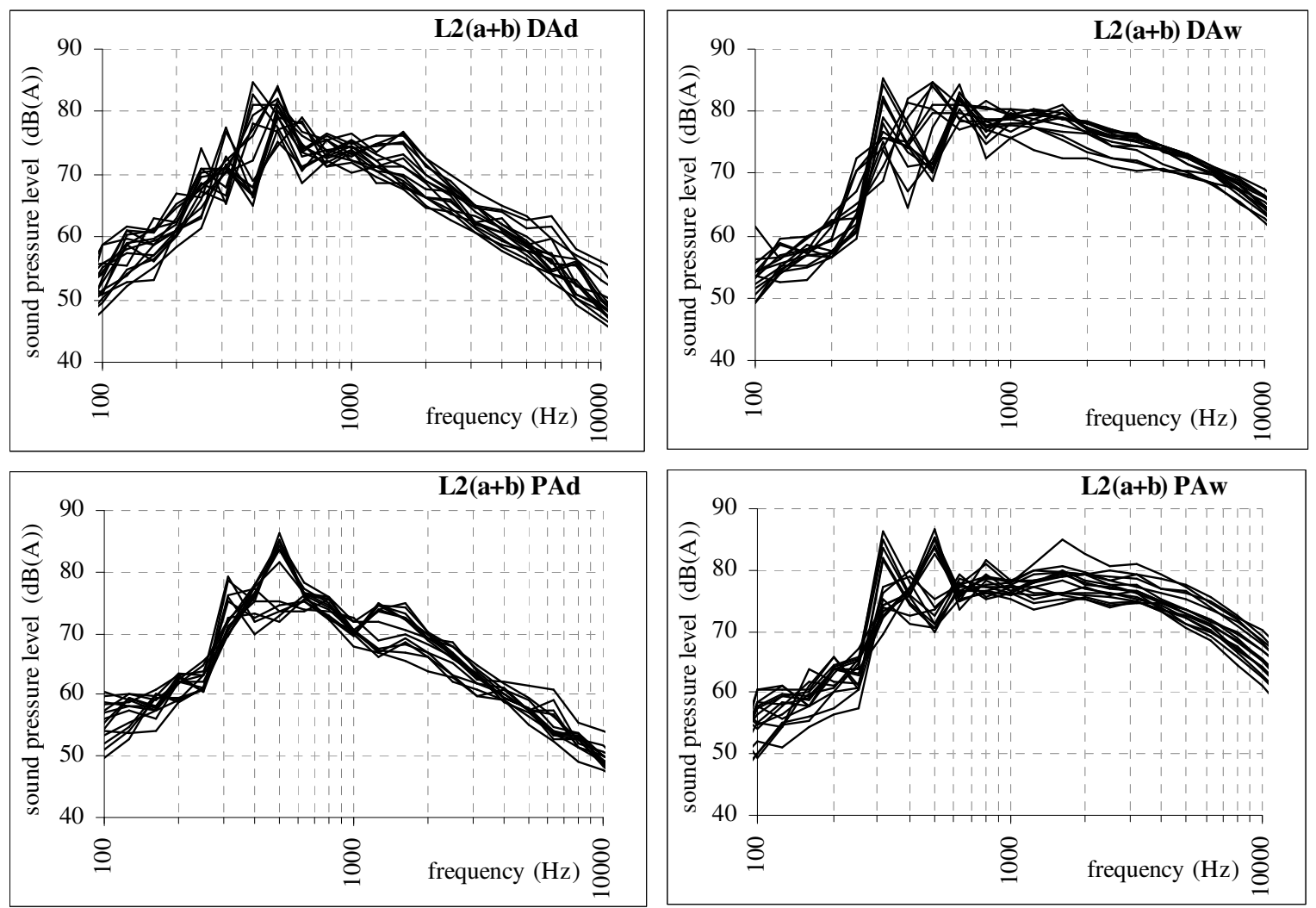

Figure 7 - Noise spectrum for heavy vehicles (medium speed level) 
Table 1 - Main properties of the surface

\begin{tabular}{|c|c|c|}
\hline Property & Porous Asphalt & Dense Asphalt \\
\hline Maximum aggregate size & $15 \mathrm{~mm}$ & $16 \mathrm{~mm}$ \\
\hline Binder content & $4.5 \%$ & $5.1 \%$ \\
\hline Porosity & $22.0 \%$ & $4.8 \%$ \\
\hline Mean texture Depth & $1.2-1.6 \mathrm{~mm}$ & $0.7-1.0 \mathrm{~mm}$ \\
\hline Friction (British Pendulum) & $0.65-0.80 \mathrm{BPN}$ & $0.65-0.70 \mathrm{BPN}$ \\
\hline
\end{tabular}


Table 2 - Regression parameters used for the estimation of vehicle sound levels for the reference speeds within the medium speed level

\begin{tabular}{|c|c|c|c|c|c|c|c|c|c|c|c|c|}
\hline \multirow[t]{2}{*}{ Parameter } & \multicolumn{3}{|c|}{$\begin{array}{c}\text { Dense asphalt - dry } \\
\text { (DAd) }\end{array}$} & \multicolumn{3}{|c|}{$\begin{array}{c}\text { Porous asphalt - dry } \\
\text { (PAd) }\end{array}$} & \multicolumn{3}{|c|}{$\begin{array}{l}\text { Dense asphalt - wet } \\
\text { (DAw) }\end{array}$} & \multicolumn{3}{|c|}{$\begin{array}{c}\text { Porous asphalt - wet } \\
\text { (PAw) }\end{array}$} \\
\hline & L1 & L2a & L2b & L1 & L2a & $\mathrm{L} 2 \mathrm{~b}$ & L1 & $\mathrm{L} 2 \mathrm{a}$ & L2b & L1 & L2a & L2b \\
\hline Number of vehicles & 24 & 8 & 8 & 23 & 6 & 8 & 19 & 9 & 7 & 19 & 9 & 7 \\
\hline Reg. line intercept & 21.6 & 49.3 & 10.1 & -2.2 & 5.7 & -67.6 & 19.3 & -44.4 & -15.8 & 22.1 & -125.2 & -75.6 \\
\hline Reg. line slop & 28.0 & 18.4 & 40.0 & 39.8 & 40.3 & 80.0 & 33.2 & 69.5 & 54.6 & 30.2 & 111.4 & 85.5 \\
\hline Correlation coefficient & 0.6 & 0.6 & 0.8 & 0.7 & 0.7 & 0.7 & 0.7 & 0.9 & 0.6 & 0.6 & 0.7 & 0.7 \\
\hline Aver. sound level $(\mathrm{dB})$ & 75.6 & 83.8 & 86.3 & 76.1 & 82.8 & 87.1 & 84.6 & 89.0 & 89.7 & 81.5 & 88.8 & 89.8 \\
\hline Std. dev. of sound level & 1.5 & 0.6 & 1.2 & 1.7 & 0.8 & 0.5 & 0.8 & 1.1 & 0.6 & 1.0 & 1.5 & 0.6 \\
\hline Average speed $(\mathrm{km} / \mathrm{h})$ & 85 & 75 & 80 & 93 & 82 & 86 & 93 & 83 & 86 & 92 & 84 & 86 \\
\hline Std. dev. of speed & 7.0 & 3.0 & 5.0 & 6.0 & 3.0 & 1.0 & 4.0 & 3.0 & 1.0 & 4.0 & 2.0 & 1.0 \\
\hline Reference speed $(\mathrm{km} / \mathrm{h})$ & 80 & 70 & 70 & 80 & 70 & 70 & 80 & 70 & 70 & 80 & 70 & 70 \\
\hline $\begin{array}{l}\text { Vehicle sound level at } \\
\text { ref. speed }\end{array}$ & 74.9 & 83.3 & 83.9 & 73.5 & 80.0 & 80.1 & 82.5 & 83.8 & 84.9 & 79.6 & 80.3 & 82.1 \\
\hline
\end{tabular}


Table 3 - Regression parameters used for the estimation of vehicle sound levels for the reference speeds within the high speed level

\begin{tabular}{|c|c|c|c|c|c|c|c|c|c|c|c|c|}
\hline Parameter & \multicolumn{3}{|c|}{$\begin{array}{l}\text { Dense asphalt - dry } \\
\text { (DAd) }\end{array}$} & \multicolumn{3}{|c|}{$\begin{array}{c}\text { Porous asphalt - dry } \\
\text { (PAd) }\end{array}$} & \multicolumn{3}{|c|}{$\begin{array}{l}\text { Dense asphalt - wet } \\
\text { (DAw) }\end{array}$} & \multicolumn{3}{|c|}{$\begin{array}{c}\text { Porous asphalt - wet } \\
\text { (PAw) }\end{array}$} \\
\hline Number of vehicles & 21 & 8 & 8 & 11 & 6 & 8 & 16 & 9 & 7 & 16 & 9 & 7 \\
\hline Reg. line slop & 71.3 & 18.4 & 40.0 & 24.4 & 40.3 & 80.0 & 36.0 & 69.5 & 54.6 & 13.3 & 111.4 & 85.5 \\
\hline Correlation coefficient & 0.9 & 0.6 & 0.8 & 0.6 & 0.7 & 0.7 & 0.6 & 0.9 & 0.6 & 0.6 & 0.7 & 0.7 \\
\hline Aver. sound level (dB) & 79.7 & 83.8 & 86.3 & 77.5 & 82.8 & 87.1 & 86.8 & 89.0 & 89.7 & 83.1 & 88.8 & 89.8 \\
\hline Average speed $(\mathrm{km} / \mathrm{h})$ & 111 & 75 & 80 & 119 & 82 & 86 & 112 & 83 & 86 & 112 & 84 & 86 \\
\hline Std. dev. of speed & 6.0 & 3.0 & 5.0 & 6.0 & 3.0 & 1.0 & 5.0 & 3.0 & 1.0 & 6.0 & 2.0 & 1.0 \\
\hline Reference speed $(\mathrm{km} / \mathrm{h})$ & 110 & 85 & 85 & 110 & 85 & 85 & 110 & 85 & 85 & 110 & 85 & 85 \\
\hline $\begin{array}{l}\text { Vehicle sound level at } \\
\text { reference speed }\end{array}$ & 79.3 & 84.8 & 87.3 & 76.8 & 83.5 & 86.8 & 86.6 & 89.7 & 89.5 & 83.0 & 89.7 & 89.4 \\
\hline
\end{tabular}


Table 4-Differences of the sound level at reference speeds

\begin{tabular}{|c|c|c|c|c|c|}
\hline Vehicle & $\begin{array}{c}\text { Ref. } \\
\text { speed } \\
(\mathrm{km} / \mathrm{h})\end{array}$ & $\begin{array}{c}\text { PAw } \\
\text { PAd }\end{array}$ & $\begin{array}{c}\text { DAw } \\
\text { DAd }\end{array}$ & $\begin{array}{c}\text { DAd } \\
\text { PAd }\end{array}$ & $\begin{array}{c}\text { DAw } \\
\text { PAw }\end{array}$ \\
\hline L1 & 80 & $\mathbf{6 . 1}$ & $\mathbf{7 . 6}$ & 1.4 & $\mathbf{2 . 9}$ \\
\hline L2a & 70 & 0.3 & 0.5 & 3.3 & 2.5 \\
\hline L2b & 70 & 2.0 & 1.0 & 3.8 & 2.8 \\
\hline L1 & 110 & $\mathbf{6 . 2}$ & $\mathbf{7 . 3}$ & 2.5 & $\mathbf{3 . 6}$ \\
\hline L2a & 85 & 3.2 & 4.9 & 1.3 & 0.0 \\
\hline L2b & 85 & 2.6 & 2.2 & 0.5 & 0.1 \\
\hline
\end{tabular}


Table 5 - Variation of the SPBI

\begin{tabular}{|c|c|c|c|c|c|c|c|c|}
\hline \multirow{2}{*}{$\begin{array}{c}\text { Speed } \\
\text { level }\end{array}$} & \multicolumn{7}{|c|}{ SPBI (dB(A)) } \\
\cline { 2 - 8 } & PAd & DAd & PAw & DAw & PAw - PAd & DAw - DAd & DAd - PAd & DAw - PAw \\
\hline Medium & 76.1 & 78.9 & 80.2 & 83.1 & 4 & 4 & 3 & 3 \\
\hline High & 82.9 & 83.9 & 86.8 & 88.3 & 4 & 4 & 1 & 1.5 \\
\hline
\end{tabular}

